\title{
Impactos do crescimento da produção de cana-de-açúcar na agricultura dos oito maiores estados produtores ${ }^{1}$
}

\author{
Cristiane de Jesus Aguiar ${ }^{2}$, Paulo Marcelo de Souza ${ }^{3}$ \\ http://dx.doi.org/10.1590/0034-737X201461040006
}

\begin{abstract}
RESUMO
Nesta pesquisa, buscou-se analisar o processo de substituição de culturas, ocorrido nos principais estados produtores de cana-de-açúcar, no período de 2000 a 2010, utilizando o modelo shift-share. Os estados de Alagoas, Goiás, Mato Grosso, Mato Grosso do Sul, Minas Gerais, Paraná, Pernambuco e São Paulo foram considerados na análise. De modo geral, os resultados mostram que a agricultura desses estados foi afetada pela forte expansão da área cultivada com cana-de-açúcar e com soja. Esse crescimento baseou-se, em parte, na substituição de outros produtos, principalmente arroz, feijão e milho, além de café, algodão e laranja. Apesar disso, os ganhos de produtividade contribuíram para reduzir, ou mesmo superar, os efeitos da perda de área dos produtos substituídos. Porém, a agricultura dos estados mais afetados pelo crescimento da participação da cana-de-açúcar e da soja tornou-se menos diversificada e, portanto, mais exposta a eventuais crises no mercado dos produtos em que passou a se basear.
\end{abstract}

Palavras-chave: cana-de-açúcar, shift-share, produção de alimentos.

\section{ABSTRACT \\ Impacts of the increase in sugarcane production on the agriculture of the main producing States}

This study analyzes, using the shift-share model, the process of crop replacemnt in the main sugar cane producer states in Brasil, from 2000 to 2010. The states of Alagoas, Goiás, Mato Grosso, Mato Grosso do Sul, Minas Gerais, Paraná, Pernambuco and São Paulo were considered in the analysis. The results showed a significant expansion of the area cultivated with sugarcane and soybean in the states studied. This growth was based, partially, on the replacement of other produce, mainly rice, beans and maize, as well as coffee, cotton and orange. Despite this, the productivity gains contributed to reduce, or even overcome the effects of the area loss in the replaced produce. However, the agriculture of the states most affected by the increase in the share of canesugar and soybean become less diverse and, therefore, more exposed to potential crises in the market of these new produce.

Key words: sugarcane, shift-share, food production.

\footnotetext{
Recebido para publicação em 24/08/2012 e aprovado em 20/11/2013.

${ }^{1}$ Este trabalho é parte da dissertação de mestrado da primeira autora.

${ }^{2}$ Engenheira de Produção, Mestre. Universidade Estadual do Norte Fluminense, Avenida Alberto Lamego, 2000, 28015-6013, Campos dos Goytacazes, Rio de Janeiro, Brasil. cristianeja_2@hotmail.com

${ }^{3}$ Engenheiro-Agrônomo, Doutor. Universidade Estadual do Norte Fluminense, Avenida Alberto Lamego, 2000, 28015-6013, Campos dos Goytacazes, Rio de Janeiro, Brasil. pmsouza@uenf.br (autor para correspondência).
} 


\section{INTRODUÇÃO}

Nos últimos anos, vem sendo observada forte expansão da área cultivada com cana-de-açúcar, incentivada pelas perspectivas da produção do etanol. Com a necessidade de diminuir a dependência dos combustíveis de origem fóssil, aliada à preocupação com as questões ambientais, o uso do etanol está tomando proporções mundiais, estimulando a expansão do cultivo da cana-deaçúcar (Aguiar et al., 2009).

O país possui um programa de larga escala de veículos com motores que utilizam o álcool, como combustível, em forma direta (álcool hidratado), ou adicionado à gasolina (álcool anidro) (BNDES, 2008). Enquanto, no Brasil, o etanol é produzido a partir da cana-de-açúcar, os EUA produzem um volume semelhante de etanol a partir do amido do milho, processo menos eficiente, em termos de balanços energético e econômico, que depende de substanciais subsídios governamentais (Hoffmann, 2006).

Beneficiando-se desse contexto, a produção de canade-açúcar vem apresentando forte crescimento, sobretudo na última década. Essa cultura vem-se expandindo desde a implantação do Proálcool, passando por um período de estagnação, na década de 80. Porém, a partir de 2001, essa produção passou a se elevar aceleradamente, mais do que dobrando no final da década (Ministério da Agricultura, Pecuária e Abastecimento, 2009).

A rápida expansão do setor sucroalcooleiro tem gerado uma série de preocupações e resistências. A monocultura, o aumento das queimadas e seus efeitos nocivos sobre a saúde humana, a degradação das condições de trabalho, o intenso fluxo migratório e seus efeitos negativos sobre as condições de vida nas cidades-dormitórios, entre outros aspectos, têm sido frequentemente questionados (Palomino et al., 2008). Apesar das potencialidades do setor, seus possíveis impactos, como a pressão sobre a floresta amazônica, o aumento das queimadas, o deslocamento da produção de alimentos e os impactos na estrutura fundiária devem ser considerados (Libardi \& Cardoso, 2007).

Um dos questionamentos associados à expansão da área de cana-de-açúcar são os possíveis efeitos sobre a produção de alimentos. Conforme Hoffmann (2006), em decorrência da competição pelo uso dos recursos, o rápido crescimento da produção de etanol no Brasil produz impactos sobre o preço de alimentos. Embora existam terras ociosas ou mal aproveitadas, que podem ser utilizadas para a cana-de-açúcar, é provável que somente quando estimulados por preços mais elevados os proprietários dessas terras decidam aproveitá-las melhor. Por outro lado, há efeitos positivos da produção de etanol, em termos de crescimento econômico e de geração de empregos e de renda. Nessa linha, segundo o autor, é improvável que eventuais aumentos de preços de alimentos tenham efeitos que cheguem a anular ou superar os efeitos benéficos do crescimento econômico, associados à expansão da agroindústria canavieira (Hoffmann, 2006)

De acordo com Kohlhepp (2010), a crítica geral feita ao Brasil, de usar áreas de plantio para a produção de etanol, em lugar de cultivá-las com alimentos, também não é correta. A título de exemplo, segundo o autor, no Estado de São Paulo, a expansão da cana-de-açúcar entre os anos de 1990 e 2008 deu-se sobre áreas de pastagem e, por outro lado, a redução da área de produção de alimentos foi compensada pelo aumento da produtividade. Segundo o autor, o aumento dos preços dos alimentos básicos, no Brasil, deve ser atribuído, especialmente, ao aumento do preço do petróleo, dos combustíveis, adubos, pesticidas e custos de transporte, bem como à especulação nos mercados de capitais, e não à diminuição de áreas de plantio e da produção de gêneros alimentícios.

Segundo Carvalho (2007), as possibilidades de deslocamento das áreas atualmente ocupadas com plantio de cereais, no Brasil, graças ao aumento relativo dos preços das terras, ainda são bastante favoráveis, em virtude de grandes extensões de terras agricultáveis, passíveis de serem postas em produção, inclusive as áreas com pastagens para criação extensiva de bovinos. No entanto, há possibilidade de que essa expansão conduza à redução da produção de alimentos e, segundo o autor, já há tendência ao aumento das importações de alimentos no País. Analisando o processo de substituição de culturas na região Centro-Oeste, Correa (2013) constatou que a expansão da cana-de-açúcar nessa região vem correndo em áreas antes destinadas à produção de arroz e o feijão, assim como em áreas anteriormente ocupadas com pastagens naturais. Segundo a autora, essa expansão induz à migração da pecuária para outras regiões, muitas das quais sob a influência do bioma Amazônia.

Diante dos possíveis impactos da expansão da produção de cana-de-açúcar sobre os demais cultivos, objetiva-se, neste trabalho, analisar as mudanças ocorridas na composição da produção agrícola, nos principais estados produtores de cana-de-açúcar, no período de 2000 a 2010. Pretende-se abordar os efeitos da expansão da produção de cana-de-açúcar sobre a produção dos demais gêneros, buscando aferir a magnitude do processo de substituição de culturas, em especial daquelas destinadas ao abastecimento do mercado interno.

\section{MATERIAL E MÉTODOS}

Para a análise das alterações na composição da produção agrícola, foi empregado o modelo shift-share (Yokoyama et al., 1989). Essa metodologia possibilita de- 
compor a variação da área nos efeitos escala e substituição, a partir dos quais se pode aquilatar em que medida a variação da área ocupada com cada produto deve-se à alteração da área total ou é devida à substituição de uma atividade por outra.

No modelo, admite-se que a variação da área total ocupada por um produto $j$ qualquer $(j=1,2, \ldots, n)$, ocorrida no intervalo de tempo compreendido entre $t=0$ e $t=T$, pode ser representada pela expressão:

$A_{j T}-A_{j 0}$

a qual, escrita de outra forma, possibilita a decomposição do efeito área em dois efeitos:

$A_{j T}-A_{j 0}=\left(\gamma A_{j 0}-A_{j 0}\right)+\left(A_{j T}-A_{j 0}\right)$

em que:

$\left(\gamma A_{j 0}-A_{j 0}\right)=$ efeito escala, expresso em hectares;

$\left(A_{j T}-\gamma A_{j 0}\right)=$ efeito substituição, expresso em hectares.

Em (2), $\gamma$ é o coeficiente que mede a modificação da área total cultivada $(A T)$ com todos os produtos considerados na análise (dimensão do sistema), entre os períodos inicial $(t=0)$ e final $(t=T)$, sendo ele obtido por:

$\gamma=A T_{T} / A T_{0}$

O efeito substituição permite observar o comportamento da participação do produto dentro do sistema, sendo ele negativo no caso da ocorrência de queda da participação do produto considerado, e positivo, em situação oposta. O primeiro caso implica que o produto em questão foi substituído no sistema por outras atividades, ao passo que, na segunda situação, o efeito substituição positivo indica que aquele produto substituiu outras atividades dentro do sistema.

Uma vez que no sistema de produção somente se verifica o efeito escala, a soma dos efeitos substituição deve ser nula, ou seja:

$\sum_{j=1}^{\mathrm{n}}\left(\mathrm{A}_{\mathrm{jT}}-\gamma A_{j 0}\right)=0$

Descritas as mudanças na área dos produtos selecionados, pretende-se também verificar em que medida elas impactaram a produção. Em termos específicos, pretendese decompor a taxa de crescimento da produção nos efeitos área e rendimento. Para tanto, foram calculadas as taxas anuais médias de variação da área $\left(r_{A}\right)$, do rendimento $\left(r_{R}\right)$ e da produção $\left(r_{Q}\right)$ do j-ésimo produto, em percentagem ao ano, mediante as expressões.

$r_{A j}=\left(\sqrt[T]{\frac{A_{j T}}{A_{j 0}}}-1\right) \times 100$

$$
\begin{aligned}
& r_{R_{j}}=\left(\sqrt[T]{\frac{R_{j T}}{R_{j 0}}}-1\right) \times 100 \\
& r_{Q_{j}}=\left(\sqrt[T]{\frac{Q_{j T}}{Q_{j 0}}}-1\right) \times 100
\end{aligned}
$$

em que, para $t$ variando entre os anos inicial $t=0$ e final $t=T$ :

$\mathrm{A}_{\mathrm{jt}}=$ área cultivada do j-ésimo produto no instante $\mathrm{t}$;

$\mathrm{R}_{\mathrm{jt}}=$ rendimento do j-ésimo produto no instante $\mathrm{t}$;

$\mathrm{Q}_{\mathrm{jt}}=$ produção total do j-ésimo produto no instante $\mathrm{t}$.

Para sintetizar as mudanças ocorridas no sistema produtivo de cada estado, foi calculado o Índice de Diversificação $(D)$. No presente contexto, esse índice foi calculado a partir das participações de cada produto $i$ na área total do sistema de produção do estado, em cada ano $t$ $\left(S_{i t}\right)$, mediante a expressão (Gasques et al., 2010):

$D=\frac{1}{\sum S_{i t}^{2}}$

Esse índice, que assume o valor 1,0, caso a região se especialize em um único produto, cresce com o aumento da diversificação.

A escolha dos estados incluídos na análise baseou-se na importância de cada um na produção de cana-de-açúcar. Mediante esse critério, foram escolhidos os estados Mato Grosso, Mato Grosso do Sul, Goiás, Pernambuco, Minas Gerais, Paraná, Alagoas e São Paulo.

A seleção das culturas abordadas foi feita com base na participação, de cada uma delas, na área total colhida com culturas no conjunto dos estados, bem como na importância de alguns produtos para alguns estados, individualmente ${ }^{1}$. Com esse critério, foram consideradas as culturas: algodão herbáceo, amendoim, arroz, aveia, banana, batatainglesa, borracha, café, cana-de-açúcar, castanha de caju, cebola, cevada, coco-da-baía, erva mate, feijão, fumo, laranja, limão, mandioca, manga, melancia, milho, soja, sorgo, trigo e uva. Em conjunto, essas culturas respondem por mais de $95 \%$ da área colhida, com culturas permanentes e temporárias, em cada estado, e por cerca de $60 \%$ da área colhida total dessas culturas, no Brasil.

As variáveis relativas a área colhida e quantidade produzida, necessárias aos cálculos, foram obtidas nos Censos Agropecuários e no Sistema de Recuperação Automática - SIDRA, do Instituto Brasileiro de Geografia e Estatística (IBGE, 2011).

A importância de certos produtos restringe-se a apenas alguns dos estados analisados. Em Pernambuco, são importantes as participações na área das culturas coco-da-baía, En Pernanico, são importantes as paricipaçös na área das culturas coco-da-baía, manga, castanha de caju, cebola, uva e nolancia. En Alagoas, é significativa a participação das culturas coco-da-baía e fumo. Em São Paulo, a participação da cultura de borracha e limão também é importante, ao passo que, no Paraná, destaca-se também a participação das culturas fumo, cevada e erva-mate. 


\section{RESULTADOS E DISCUSSÃO}

Na Tabela 1, encontram-se os resultados da decomposição da mudança na área colhida (efeitos escala e substituição) e da taxa de crescimento da produção (efeitos área e rendimento), para o Estado de Alagoas. No período, a agricultura do Estado de Alagoas foi afetada por redução da dimensão de seu sistema produtivo, caracterizada pelo efeito escala negativo. Apesar disso, e em razão da substituição de culturas, verifica-se algum crescimento na área colhida com castanha de caju, laranja, melancia, manga, amendoim, limão e banana. Feijão, milho, fumo e algodão, mas também mandioca, arroz, coco-da-baía e café perderam área por substituição no sistema produtivo. Cerca de $92 \%$ da área cedida por essas culturas no processo de substituição foi incorporada à produção de cana-de-açúcar, que, apesar disso, teve sua área colhida reduzida, no período, dado o predomínio do efeito escala. Essa redução foi também observada por Moreira (2010), que, no período de 1990 a 2008, constatou queda de $23 \%$ da área cultivada ocupada com essa cultura, em Alagoas.

Nesse estado, houve queda na produção da maior parte das culturas, com exceção de amendoim, castanha de caju, fumo, laranja, limão e melancia. Enquanto a produção de limão cresceu pelo aumento da área colhida, no caso do fumo, o aumento da produtividade impediu que a queda da área resultasse em queda da produção. Nos demais casos, o crescimento da produção deveu-se tanto ao aumento da área quanto aos incrementos de produtividade.
De todo o modo, houve queda da produção das demais culturas, devida à redução da área colhida e à queda na produtividade, ou a ambos.

No Estado de Goiás, houve expansão da área colhida da grande maioria das culturas abordadas, podendo-se destacar soja, cana-de-açúcar, sorgo e milho (Tabela 2). Conjuntamente, essas culturas tiveram um crescimento de aproximadamente 1.5 milhão de hectares de área colhida do estado. As únicas culturas que perderam área no período foram algodão, arroz e, em menor proporção, manga.

Quando se considera a proporção com que cada um dos produtos analisados participa da área permutada entre culturas, cedendo ou tomando espaço de outras, verifica-se que milho, algodão e arroz respondem por quase $90 \%$ da área cedida a outras culturas. Nos casos de algodão e arroz, houve perda na área total colhida. No milho, que cedeu aproximadamente $55 \%$ da área permutada no sistema, essa perda foi compensada pelo efeito escala positivo. As áreas cedidas por essas culturas foram ocupadas principalmente por cana-de-açúcar e soja. Juntas, essas duas culturas ocuparam cerca de $97 \%$ da área substituída no sistema.

Apesar do efeito substituição, a ampliação do sistema produtivo em Goiás contribuiu para aumento quase generalizado da área cultivada. A expansão da área, acompanhada de crescimento dos rendimentos, implicou taxas positivas de aumento da produção para a maior parte das culturas. As únicas exceções foram arroz e algodão, cuja

Tabela 1 - Decomposição da variação da área (efeitos escala e substituição), em ha, e da taxa de crescimento da produção (efeitos área e rendimento), em \%, das principais culturas no Estado de Alagoas, período de 2000-2010

\begin{tabular}{|c|c|c|c|c|c|c|c|}
\hline \multirow{3}{*}{ Culturas } & \multicolumn{3}{|c|}{ Variação da área } & \multirow{3}{*}{$\%^{5}$} & \multicolumn{3}{|c|}{ Variação da produção } \\
\hline & \multirow{2}{*}{$\begin{array}{c}\text { Variação } \\
\text { total }\end{array}$} & \multicolumn{2}{|c|}{ Efeitos } & & \multirow{2}{*}{ Área } & \multirow{2}{*}{ Rendim. } & \multirow{2}{*}{ Total } \\
\hline & & Escala & Substituição & & & & \\
\hline Algodão herbáceo & $-5011,00$ & $-711,20$ & $-4299,80$ & $-10,66$ & $-15,34$ & $-1,66$ & $-17,00$ \\
\hline Amendoim & 20,00 & $-7,62$ & 27,62 & 0,07 & 2,82 & 10,14 & 12,96 \\
\hline Arroz & $-3411,00$ & $-742,74$ & $-2668,26$ & $-6,62$ & $-7,25$ & $-0,89$ & $-8,13$ \\
\hline Banana & 5,00 & $-476,14$ & 481,14 & 1,19 & 0,01 & $-5,64$ & $-5,63$ \\
\hline Café & $-33,00$ & $-4,39$ & $-28,61$ & $-0,07$ & $-19,49$ & 11,20 & $-8,29$ \\
\hline Cana-de-açúcar & $-14430,00$ & $-51766,99$ & 37336,99 & 92,57 & $-0,33$ & $-0,99$ & $-1,31$ \\
\hline Castanha de caju & 1167,00 & $-32,00$ & 1199,00 & 2,97 & 18,28 & 4,02 & 22,30 \\
\hline Coco-da-baía & $-2568,00$ & $-1749,30$ & $-818,70$ & $-2,03$ & $-1,86$ & 1,71 & $-0,14$ \\
\hline Feijão & $-27788,00$ & $-9484,17$ & $-18303,83$ & $-45,38$ & $-4,04$ & $-0,39$ & $-4,43$ \\
\hline Fumo & $-7441,00$ & $-2045,71$ & $-5395,29$ & $-13,38$ & $-5,46$ & 5,75 & 0,28 \\
\hline Laranja & 596,00 & $-434,44$ & 1030,44 & 2,55 & 1,49 & 1,64 & 3,13 \\
\hline Limão & 20,00 & $-1,04$ & 21,04 & 0,05 & 11,96 & $-7,77$ & 4,19 \\
\hline Mandioca & $-4710,00$ & $-2900,03$ & $-1809,97$ & $-4,49$ & $-2,06$ & 0,81 & $-1,25$ \\
\hline Manga & 28,00 & $-104,77$ & 132,77 & 0,33 & 0,30 & $-1,52$ & $-1,21$ \\
\hline Melancia & 104,00 & $-0,92$ & 104,92 & 0,26 & 30,65 & 3,46 & 34,11 \\
\hline Milho & $-13604,00$ & $-6594,54$ & $-7009,46$ & $-17,38$ & $-2,64$ & $-3,13$ & $-5,77$ \\
\hline
\end{tabular}

Fonte: elaborada pelos autores, a partir de dados do IBGE.

${ }^{5}$ Esse percentual refere-se, nesta e nas demais tabelas, à participação da área que cada atividade cede ou toma às demais na área total substituída. 
produção caiu em função da redução da área colhida, e manga, cuja área e rendimento declinaram.

Esses resultados estão de acordo com os de Silva et al. (2010), que constataram forte avanço da cultura da cana-de-açúcar em Goiás, no período de 1990 a 2009. Abordando o período de 1996 a 2006, Hernández (2008) observou crescimento expressivo da área cultivada de canade-açúcar e soja, além de feijão, culturas que passaram a ocupar áreas antes destinadas a milho, arroz e pastagens. Também Ávila et al. (2009), analisando o avanço da canade-açúcar, no município goiano de Rubiataba, constataram um processo de substituição das chamadas "lavouras brancas" (milho, arroz, feijão, café), bem como da pecuária. Porém, para o conjunto do estado, Silva et al. (2010) concluíram que a expansão da cana-de-açúcar não impactou significativamente a produção de alimentos, uma vez que os ganhos de produtividade contribuíram para contrabalançar a ocupação de novas áreas pela cana-deaçúcar.

Em Mato Grosso, houve expansão da área colhida de algodão herbáceo, cana-de-açúcar, feijão, milho e soja, movimento que incorporou cerca de 4.5 milhões de hectares de área ao cultivo desses produtos (Tabela 3). Houve ainda expansão da área colhida com amendoim, caju, cocoda-baía e mandioca, com incrementos de menor magnitu- de. A cultura que mais perdeu área foi o arroz, seguida de sorgo, café e banana. Como esse período foi marcado por crescimento do sistema de produção no estado, isto é, o efeito escala foi positivo, essas culturas perderam área em virtude de sua substituição por outras atividades. Também a cana-de-açúcar foi, em menor proporção, substituída no sistema. Porém, essa perda de área foi compensada pelo efeito escala positivo. Dentre as culturas que mais incorporaram área por substituição destacam-se milho e soja, que ocuparam mais de $95 \%$ da área permutada no sistema.

Nesse estado, houve, de modo geral, queda da produção dos produtos cuja área colhida reduziu-se em decorrência da substituição por outras culturas, como é o caso de arroz, aveia, banana, borracha, café, laranja, manga, melancia, sorgo, trigo e uva. Ainda que tenha ocorrido aumento expressivo da produtividade para alguns desses produtos, esse incremento não foi suficiente para assegurar elevação da produção, no período. Nos demais casos, o aumento da área, concomitantemente ao crescimento da produtividade (exceto para algodão e soja), assegurou taxas positivas e elevadas de crescimento da produção.

No Estado de Mato Grosso do Sul ocorreu expansão da área cultivada com soja, cana-de-açúcar, milho e feijão, para citar as mais importantes (Tabela 4). Juntas, essas

Tabela 2 - Decomposição da variação da área (efeitos escala e substituição), em ha, e da taxa de crescimento da produção (efeitos área e rendimento), em \%, das principais culturas no Estado de Goiás, período de 2000-2010

\begin{tabular}{|c|c|c|c|c|c|c|c|}
\hline \multirow{3}{*}{ Culturas } & \multicolumn{3}{|c|}{ Variação da área } & \multirow{3}{*}{$\%$} & \multicolumn{3}{|c|}{ Variação da produção } \\
\hline & \multirow{2}{*}{$\begin{array}{c}\text { Variação } \\
\text { total }\end{array}$} & \multicolumn{2}{|c|}{ Efeitos } & & \multirow{2}{*}{ Área } & \multirow{2}{*}{ Rendim. } & \multirow{2}{*}{ Total } \\
\hline & & Escala & Substituição & & & & \\
\hline Algodão herbáceo & $-52809,00$ & 44559,35 & $-97368,35$ & $-14,7$ & $-7,77$ & 4,38 & $-3,38$ \\
\hline Amendoim & 410,00 & 0,00 & 410,00 & 0,06 & 0,00 & 0,00 & 0,00 \\
\hline Arroz & $-59952,00$ & 69261,00 & $-129213,00$ & $-19,5$ & $-5,02$ & 2,20 & $-2,82$ \\
\hline Banana & 1213,00 & 5910,04 & $-4697,04$ & $-0,71$ & 0,91 & 1,15 & 2,07 \\
\hline Batata-inglesa & 5619,00 & 539,96 & 5079,04 & 0,77 & 19,65 & 5,08 & 24,73 \\
\hline Borracha & 2053,00 & 572,21 & 1480,79 & 0,22 & 10,45 & 4,19 & 14,65 \\
\hline Café & 6040,00 & 1836,41 & 4203,59 & 0,63 & 9,72 & 1,34 & 11,07 \\
\hline Cana-de-açúcar & 439480,00 & 64124,96 & 375355,04 & 56,66 & 15,41 & 1,38 & 16,79 \\
\hline Cebola & 1171,00 & 17,97 & 1153,03 & 0,17 & 41,30 & 1,87 & 43,17 \\
\hline Coco-da-baía & 1198,00 & 59,89 & 1138,11 & 0,17 & 26,38 & 1,89 & 28,27 \\
\hline Feijão & 6769,00 & 51682,46 & $-44913,46$ & $-6,78$ & 0,60 & 3,12 & 3,72 \\
\hline Fumo & 200,00 & 0,00 & 200,00 & 0,03 & 0,00 & 0,00 & 0,00 \\
\hline Laranja & 244,00 & 3044,86 & $-2800,86$ & $-0,42$ & 0,36 & 0,91 & 1,28 \\
\hline Limão & 65,00 & 218,84 & $-153,84$ & $-0,02$ & 1,30 & 1,06 & 2,36 \\
\hline Mandioca & 4201,00 & 7811,87 & $-3610,87$ & $-0,55$ & 2,25 & 0,77 & 3,02 \\
\hline Manga & $-155,00$ & 105,96 & $-260,96$ & $-0,04$ & $-10,36$ & $-4,23$ & $-14,60$ \\
\hline Melancia & 1629,00 & 2819,57 & $-1190,57$ & $-0,18$ & 2,42 & 2,95 & 5,37 \\
\hline Milho & 20197,00 & 386928,04 & $-366731,04$ & $-55,36$ & 0,24 & 2,27 & 2,51 \\
\hline Soja & 954534,00 & 686955,24 & 267578,76 & 40,39 & 5,09 & 0,80 & 5,89 \\
\hline Sorgo & 69458,00 & 81016,59 & $-11558,59$ & $-1,74$ & 3,46 & 4,38 & 7,84 \\
\hline Trigo & 8937,00 & 3172,94 & 5764,06 & 0,87 & 9,33 & 15,75 & 25,08 \\
\hline Uva & 138,00 & 1,84 & 136,16 & 0,02 & 43,51 & 3,46 & 46,97 \\
\hline
\end{tabular}

Fonte: elaborada pelos autores, a partir de dados do IBGE.

Rev. Ceres, Viçosa, v. 61, n.4, p. 482-493, jul/ago, 2014 
Tabela 3 - Decomposição da variação da área (efeitos escala e substituição), em ha, e da taxa de crescimento da produção (efeitos área e rendimento), em \%, das principais culturas no Estado de Mato Grosso, período de 2000-2010

\begin{tabular}{|c|c|c|c|c|c|c|c|}
\hline \multirow{3}{*}{ Culturas } & \multicolumn{3}{|c|}{ Variação da área } & \multirow{3}{*}{$\%$} & \multicolumn{3}{|c|}{ Variação da produção } \\
\hline & \multirow{2}{*}{$\begin{array}{c}\text { Variação } \\
\text { total }\end{array}$} & \multicolumn{2}{|c|}{ Efeitos } & & \multirow{2}{*}{ Área } & \multirow{2}{*}{ Rendim. } & \multirow{2}{*}{ Total } \\
\hline & & Escala & $\overline{\text { Substituição }}$ & & & & \\
\hline Algodão herbáceo & 162370,00 & 246651,75 & $-84281,75$ & $-5,46$ & 4,98 & $-1,19$ & 3,79 \\
\hline Amendoim & 2649,00 & 515,77 & 2133,23 & 0,14 & 20,33 & 9,87 & 30,20 \\
\hline Arroz & $-463379,00$ & 668409,97 & $-1131788,97$ & $-73,26$ & $-10,37$ & 0,93 & $-9,44$ \\
\hline Aveia & $-200,00$ & 191,38 & $-391,38$ & $-0,03$ & $-50,00$ & $-50,00$ & $-100,00$ \\
\hline Banana & $-20055,00$ & 25188,41 & $-45243,41$ & $-2,93$ & $-13,69$ & 4,48 & $-9,21$ \\
\hline Borracha & $-3573,00$ & 25068,79 & $-28641,79$ & $-1,85$ & $-1,42$ & $-4,82$ & $-6,24$ \\
\hline Café & $-20137,00$ & 33800,48 & $-53937,48$ & $-3,49$ & $-8,21$ & 2,80 & $-5,41$ \\
\hline Cana-de-açúcar & 77469,00 & 129208,88 & $-51739,88$ & $-3,35$ & 4,66 & 0,91 & 5,57 \\
\hline Castanha de caju & 720,00 & 0,00 & 720,00 & 0,05 & 0,00 & 0,00 & 0,00 \\
\hline Coco-da-baía & 126,00 & 1560,70 & $-1434,70$ & $-0,09$ & 0,75 & 1,04 & 1,79 \\
\hline Feijão & 78717,00 & 27105,07 & 51611,93 & 3,34 & 14,48 & 3,94 & 18,43 \\
\hline Laranja & $-871,00$ & 1285,11 & $-2156,11$ & $-0,14$ & $-9,81$ & $-2,25$ & $-12,06$ \\
\hline Limão & $-30,00$ & 142,58 & $-172,58$ & $-0,01$ & $-2,36$ & 11,95 & 9,59 \\
\hline Mandioca & 8149,00 & 26139,56 & $-17990,56$ & $-1,16$ & 2,65 & 0,55 & 3,21 \\
\hline Manga & $-95,00$ & 257,41 & $-352,41$ & $-0,02$ & $-4,08$ & $-8,22$ & $-12,31$ \\
\hline Melancia & $-654,00$ & 1400,90 & $-2054,90$ & $-0,13$ & $-5,75$ & 0,01 & $-5,74$ \\
\hline Milho & 1469950,00 & 518439,28 & 951510,72 & 61,59 & 14,33 & 4,71 & 19,03 \\
\hline Soja & 3320004,00 & 2781172,15 & 538831,85 & 34,88 & 7,92 & $-0,01$ & 7,91 \\
\hline Sorgo & $-23205,00$ & 99369,00 & $-122574,00$ & $-7,93$ & $-2,52$ & 1,76 & $-0,76$ \\
\hline Trigo & $-720,00$ & 956,90 & $-1676,90$ & $-0,11$ & $-12,33$ & 6,00 & $-6,33$ \\
\hline Uva & $-147,00$ & 223,91 & $-370,91$ & $-0,02$ & $-9,62$ & 3,99 & $-5,63$ \\
\hline
\end{tabular}

Fonte: elaborada pelos autores, a partir de dados do IBGE.

Tabela 4 - Decomposição da variação da área (efeitos escala e substituição), em ha, e da taxa de crescimento da produção (efeitos área e rendimento), em \%, das principais culturas no Estado de Mato Grosso do Sul, período de 2000-2010

\begin{tabular}{|c|c|c|c|c|c|c|c|}
\hline \multirow{3}{*}{ Culturas } & \multicolumn{3}{|c|}{ Variação da área } & \multirow{3}{*}{$\%$} & \multicolumn{3}{|c|}{ Variação da produção } \\
\hline & \multirow{2}{*}{$\begin{array}{c}\text { Variação } \\
\text { total }\end{array}$} & \multicolumn{2}{|c|}{ Efeitos } & & \multirow{2}{*}{ Área } & \multirow{2}{*}{ Rendim. } & \multirow{2}{*}{ Total } \\
\hline & & Escala & Substituição & & & & \\
\hline Algodão herbáceo & $-9710,00$ & 35921,33 & $-45631,33$ & $-10,86$ & $-2,25$ & 3,82 & 1,57 \\
\hline Amendoim & 181,00 & 226,87 & $-45,87$ & $-0,01$ & 4,83 & 3,27 & 8,10 \\
\hline Arroz & $-39558,00$ & 48983,50 & $-88541,50$ & $-21,07$ & $-8,93$ & 4,40 & $-4,52$ \\
\hline Aveia & 6865,00 & 3632,91 & 3232,09 & 0,77 & 9,33 & 4,01 & 13,34 \\
\hline Banana & $-2278,00$ & 2620,14 & $-4898,14$ & $-1,17$ & $-9,73$ & $-1,95$ & $-11,68$ \\
\hline Borracha & 318,00 & 378,86 & $-60,86$ & $-0,01$ & 5,08 & 5,11 & 10,19 \\
\hline Café & $-157,00$ & 1045,39 & $-1202,39$ & $-0,29$ & $-1,17$ & $-1,18$ & $-2,35$ \\
\hline Cana-de-açúcar & 300470,00 & 73353,66 & 227116,34 & 54,03 & 15,27 & 4,27 & 19,54 \\
\hline Cebola & $-5,00$ & 3,71 & $-8,71$ & 0,00 & $-50,00$ & $-50,00$ & $-100,00$ \\
\hline Coco-da-baía & 344,00 & 93,42 & 250,58 & 0,06 & 13,89 & $-2,70$ & 11,19 \\
\hline Erva-mate & $-349,00$ & 442,62 & $-791,62$ & $-0,19$ & $-8,42$ & 0,30 & $-8,12$ \\
\hline Feijão & 11623,00 & 8624,09 & 2998,91 & 0,71 & 7,34 & 4,95 & 12,29 \\
\hline Laranja & $-106,00$ & 464,86 & $-570,86$ & $-0,14$ & $-1,86$ & 3,20 & 1,34 \\
\hline Limão & $-1,00$ & 63,76 & $-64,76$ & $-0,02$ & $-0,12$ & $-2,92$ & $-3,03$ \\
\hline Mandioca & $-5829,00$ & 24109,92 & $-29938,92$ & $-7,12$ & $-1,97$ & 1,13 & $-0,84$ \\
\hline Manga & $-129,00$ & 106,76 & $-235,76$ & $-0,06$ & $-20,42$ & 1,55 & $-18,87$ \\
\hline Melancia & $-117,00$ & 926,76 & $-1043,76$ & $-0,25$ & $-0,97$ & $-1,42$ & $-2,39$ \\
\hline Milho & 479239,00 & 292514,55 & 186724,45 & 44,42 & 8,47 & 4,99 & 13,47 \\
\hline Soja & 632938,00 & 815076,14 & $-182138,14$ & $-43,33$ & 4,73 & 3,22 & 7,95 \\
\hline Sorgo & 2806,00 & 46527,95 & $-43721,95$ & $-10,4$ & 0,45 & 6,41 & 6,86 \\
\hline Trigo & 4617,00 & 25911,55 & $-21294,55$ & $-5,07$ & 1,29 & 6,60 & 7,89 \\
\hline Uva & $-68,00$ & 65,24 & $-133,24$ & $-0,03$ & $-14,01$ & 3,23 & $-10,78$ \\
\hline
\end{tabular}

Fonte: elaborada pelos autores, a partir de dados do IBGE. 
culturas tiveram um crescimento de 1.4 milhão de hectares na área colhida. Esse crescimento deu-se, em parte, pela incorporação de novas áreas do sistema de produção do estado, que se reflete no efeito escala positivo. Essa fonte de crescimento beneficiou, sobretudo, as culturas de feijão, soja e milho. No caso da cana-de-açúcar, a principal fonte de crescimento de sua área proveio do efeito substituição.

Além da cana-de-açúcar, o processo de substituição de culturas no estado beneficiou a cultura do milho, e, em menor proporção, aveia, coco-da-baía e feijão. A maior parte da área, permutada no sistema, foi incorporada pela cana-de-açúcar e pelo milho, que passaram a ocupar áreas de soja, principalmente, além de algodão, arroz e sorgo. No caso da soja, a perda de área foi compensada pelo efeito escala.

As culturas de arroz, banana, café, erva-mate, limão, mandioca, manga, melancia e uva apresentaram taxas negativas de crescimento da produção, no período, decorrente sobretudo da queda da área cultivada. Nos casos de algodão e laranja, a queda da área foi compensada pelas taxas positivas de crescimento da produtividade. Já os demais produtos experimentaram elevadas taxas de crescimento da produção, decorrentes dos aumentos da área cultivada e da produtividade. Esse crescimento foi especialmente elevado para cana-de-açúcar, cuja produção expandiu-se à taxa média de 19,5\% ao ano.

Os resultados obtidos para os estados da região Centro-Oeste confirmam a análise de Hernández (2008). Abordando o período de 1995 a 2006, a autora constatou, na região Centro-Oeste (exceto Goiás, analisado à parte), crescimento da área cultivada com soja, milho, cana-de-açúcar e feijão. Esse crescimento beneficiou-se da ocupação de áreas cedidas pela produção de arroz e pelas pastagens. Já no Estado de Goiás, arroz e pastagens, mas também o milho, foram substituídos pelas culturas em expansão. Em virtude dessas mudanças, os estados de Goiás, Mato-Grosso e Mato-Grosso do Sul passaram a ter maior representação na produção nacional, como demonstrado por Moreira (2010).

A cana-de-açúcar e a soja, seguidas de sorgo e café, foram as culturas que mais se expandiram no Estado de Minas Gerais, no período abordado, incorporando a seus cultivos uma área de cerca de 961 mil hectares (Tabela 5). Em parte, essa expansão decorreu da substituição de culturas no sistema do estado, processo em que perderam áreas milho, café, feijão e arroz. Embora perdendo área por efeito substituição, o café elevou sua área colhida,

Tabela 5 - Decomposição da variação da área (efeitos escala e substituição), em ha, e da taxa de crescimento da produção (efeitos área e rendimento), em \%, das principais culturas no Estado de Minas Gerais, período de 2000-2010

\begin{tabular}{|c|c|c|c|c|c|c|c|}
\hline \multirow{3}{*}{ Culturas } & \multicolumn{3}{|c|}{ Variação da área } & \multirow{3}{*}{$\%$} & \multicolumn{3}{|c|}{ Variação da produção } \\
\hline & \multirow{2}{*}{$\begin{array}{c}\text { Variação } \\
\text { total }\end{array}$} & \multicolumn{2}{|c|}{ Efeitos } & & \multirow{2}{*}{ Área } & \multirow{2}{*}{ Rendim. } & \multirow{2}{*}{ Total } \\
\hline & & Escala & Substituição & & & & \\
\hline Algodão herbáceo & $-34250,00$ & 9341,94 & $-43591,94$ & $-5,66$ & $-11,54$ & 5,89 & $-5,64$ \\
\hline Amendoim & 519,00 & 513,08 & 5,92 & 0,00 & 1,80 & 3,71 & 5,51 \\
\hline Arroz & $-78973,00$ & 24737,41 & $-103710,41$ & $-13,46$ & $-8,91$ & 1,02 & $-7,90$ \\
\hline Aveia & $-2,00$ & 0,38 & $-2,38$ & 0,00 & $-50,00$ & $-50,00$ & $-100,00$ \\
\hline Banana & $-911,00$ & 7840,78 & $-8751,78$ & $-1,14$ & $-0,22$ & 1,38 & 1,15 \\
\hline Batata-inglesa & 5967,00 & 6278,42 & $-311,42$ & $-0,04$ & 1,70 & 3,22 & 4,92 \\
\hline Borracha & 2610,00 & 292,54 & 2317,46 & 0,30 & 10,53 & 2,56 & 13,09 \\
\hline Café & 33495,00 & 188164,72 & $-154669,72$ & $-20,08$ & 0,34 & 2,04 & 2,38 \\
\hline Cana-de-açúcar & 455444,00 & 55151,10 & 400292,90 & 51,96 & 9,99 & 2,48 & 12,47 \\
\hline Cebola & 30,00 & 392,39 & $-362,39$ & $-0,05$ & 0,15 & 7,73 & 7,88 \\
\hline Coco-da-baía & 1022,00 & 298,41 & 723,59 & 0,09 & 5,38 & 10,17 & 15,55 \\
\hline Feijão & $-25238,00$ & 82670,66 & $-107908,66$ & $-14,01$ & $-0,61$ & 4,97 & 4,36 \\
\hline Fumo & $-2059,00$ & 390,12 & $-2449,12$ & $-0,32$ & $-50,00$ & $-50,00$ & $-100,00$ \\
\hline Laranja & $-7461,00$ & 7683,52 & $-15144,52$ & $-1,97$ & $-2,08$ & 6,44 & 4,37 \\
\hline Limão & 1745,00 & 254,08 & 1490,92 & 0,19 & 9,11 & 10,04 & 19,15 \\
\hline Mandioca & $-14032,00$ & 13169,78 & $-27201,78$ & $-3,53$ & $-2,24$ & 0,99 & $-1,25$ \\
\hline Manga & 1424,00 & 1302,41 & 121,59 & 0,02 & 1,97 & 7,31 & 9,28 \\
\hline Melancia & 1142,00 & 207,09 & 934,91 & 0,12 & 7,53 & 3,25 & 10,78 \\
\hline Milho & $-71043,00$ & 235045,14 & $-306088,14$ & $-39,73$ & $-0,60$ & 4,31 & 3,71 \\
\hline Soja & 420557,00 & 113691,42 & 306865,58 & 39,83 & 5,50 & 1,77 & 7,27 \\
\hline Sorgo & 52245,00 & 9243,42 & 43001,58 & 5,58 & 7,90 & 9,69 & 17,59 \\
\hline Trigo & 15703,00 & 1063,87 & 14639,13 & 1,90 & 14,26 & $-0,25$ & 14,01 \\
\hline Uva & $-49,00$ & 152,33 & $-201,33$ & $-0,03$ & $-0,62$ & $-1,51$ & $-2,14$ \\
\hline
\end{tabular}

Fonte: elaborada pelos autores, a partir de dados do IBGE.

Rev. Ceres, Viçosa, v. 61, n.4, p. 482-493, jul/ago, 2014 
alicerçado no efeito escala. A maior parte da área substituída no sistema desse estado foi incorporada por canade-açúcar e soja. Também Oliveira et al. (2010), abordando o período de 2007 a 2008, constataram avanço da canade-açúcar em Minas Gerais. Segundo os autores, o crescimento da área com essa cultura, entre os anos citados, substituiu as culturas de milho, arroz, mandioca.

Apesar disso, poucas foram as culturas do estado cuja produção declinou no período. Em função da redução da área colhida, principalmente, houve queda da produção de algodão, arroz, aveia, fumo, mandioca e uva. Os demais produtos apresentaram taxas expressivas de crescimento da produção, alicerçadas tanto no aumento da área quanto no da produtividade. A cana-de-açúcar e a soja, que ocuparam a maior parte da área substituída no sistema, cresceram a taxas de cerca de 12,5 e 7,3\%, respectivamente.

O período foi marcado, no Paraná, por redução da área colhida com mandioca, aveia, café, algodão, arroz e feijão, além de batata, manga e sorgo (Tabela 6). Como houve crescimento do sistema de produção, no período (efeito escala positivo), essas culturas perderam área por serem substituídas no sistema. O processo de substituição afe- tou também o milho, porém essa perda foi compensada pelo efeito escala positivo. Da área total permutada das culturas, no estado, a maior parte foi cedida pelo milho, principalmente, mas também por aveia, café e feijão. Por outro lado, as culturas que mais tomam área no processo de substituição foram a soja e o trigo, seguidas por canade-açúcar e fumo, em menor proporção.

Abordando a microrregião paranaense de Paranavaí, Ribeiro et al. (2013) destacam a forte expansão da canade-açúcar. Segundo os autores, no período de dez anos (1994 a 2004), a área cultivada com cana-de-açúcar triplicou. De uma situação em que mandioca e, em seguida, a cana-de-açúcar, eram as principais culturas, em termos de área plantada, além de milho, café, soja e trigo, chegou-se a outra, em que a cana-de-açúcar tornou-se predominante. Porém, conforme Libardi \& Cardoso (2007), é pouco provável que ocorra, no Paraná, a formação de um "mar de cana". Por restrições naturais, as áreas aptas ao cultivo de cana-de-açúcar no estado estão na porção norte, onde a quase totalidade da cana é produzida. E, mesmo nessas regiões, a cultura que mais se expandiu foi a soja, fato corroborado nesta pesquisa.

Tabela 6 - Decomposição da variação da área (efeitos escala e substituição), em ha, e da taxa de crescimento da produção (efeitos área e rendimento), em \%, das principais culturas no Estado do Paraná, período de 2000-2010

\begin{tabular}{|c|c|c|c|c|c|c|c|}
\hline \multirow{3}{*}{ Culturas } & \multicolumn{3}{|c|}{ Variação da área } & \multirow{3}{*}{$\%$} & \multicolumn{3}{|c|}{ Variação da produção } \\
\hline & \multirow{2}{*}{$\begin{array}{c}\text { Variação } \\
\text { total }\end{array}$} & \multicolumn{2}{|c|}{ Efeitos } & & \multirow{2}{*}{ Área } & \multirow{2}{*}{ Rendim. } & \multirow{2}{*}{ Total } \\
\hline & & Escala & Substituição & & & & \\
\hline Algodão herbáceo & $-54010,00$ & 18464,38 & $-72474,38$ & $-5,21$ & $-46,47$ & $-0,93$ & $-47,41$ \\
\hline Amendoim & 96,00 & 1359,18 & $-1263,18$ & $-0,09$ & 0,24 & 2,38 & 2,62 \\
\hline Arroz & $-39368,00$ & 27239,14 & $-66607,14$ & $-4,78$ & $-6,78$ & 6,05 & $-0,73$ \\
\hline Aveia & $-61780,00$ & 38348,69 & $-100128,69$ & $-7,19$ & $-8,07$ & 10,01 & 1,94 \\
\hline Banana & 2040,00 & 2812,19 & $-772,19$ & $-0,06$ & 2,27 & 3,11 & 5,38 \\
\hline Batata-inglesa & $-6370,00$ & 12438,01 & $-18808,01$ & $-1,35$ & $-1,93$ & 3,09 & 1,16 \\
\hline Borracha & 376,00 & 74,39 & 301,61 & 0,02 & 10,82 & 5,48 & 16,30 \\
\hline Café & $-59445,00$ & 48496,95 & $-107941,95$ & $-7,75$ & $-5,39$ & 4,45 & $-0,95$ \\
\hline Cana-de-açúcar & 298720,00 & 111643,17 & 187076,83 & 13,44 & 6,73 & 0,89 & 7,63 \\
\hline Cebola & 2446,00 & 1775,83 & 670,17 & 0,05 & 4,01 & 4,28 & 8,29 \\
\hline Cevada & 15669,00 & 10965,88 & 4703,12 & 0,34 & 4,17 & 5,98 & 10,15 \\
\hline Coco-da-baía & 200,00 & 0,00 & 200,00 & 0,01 & 0,00 & 0,00 & 0,00 \\
\hline Erva-mate & 1503,00 & 9876,97 & $-8373,97$ & $-0,6$ & 0,49 & $-5,52$ & $-5,02$ \\
\hline Feijão & $-20084,00$ & 184572,86 & $-204656,86$ & $-14,7$ & $-0,39$ & 5,21 & 4,82 \\
\hline Fumo & 45595,00 & 11570,91 & 34024,09 & 2,44 & 8,93 & 0,90 & 9,83 \\
\hline Laranja & 7361,00 & 4693,47 & 2667,53 & 0,19 & 4,43 & 2,41 & 6,84 \\
\hline Limão & 113,00 & 206,45 & $-93,45$ & $-0,01$ & 1,73 & 0,81 & 2,54 \\
\hline Mandioca & $-10642,00$ & 62398,56 & $-73040,56$ & $-5,25$ & $-0,60$ & 1,21 & 0,61 \\
\hline Manga & $-84,00$ & 227,95 & $-311,95$ & $-0,02$ & $-1,35$ & 1,60 & 0,25 \\
\hline Melancia & 1384,00 & 1142,83 & 241,17 & 0,02 & 3,53 & 0,37 & 3,90 \\
\hline Milho & 27083,00 & 760956,89 & $-733873,89$ & $-52,71$ & 0,12 & 6,19 & 6,32 \\
\hline Soja & 1621901,00 & 975265,09 & 646635,91 & 46,45 & 4,65 & 2,31 & 6,96 \\
\hline Sorgo & $-1594,00$ & 543,94 & $-2137,94$ & $-0,15$ & $-50,00$ & $-50,00$ & $-100,00$ \\
\hline Trigo & 682900,00 & 167182,37 & 515717,63 & 37,04 & 9,46 & 7,80 & 17,27 \\
\hline Uva & 211,00 & 1964,88 & $-1753,88$ & $-0,13$ & 0,36 & 2,18 & 2,55 \\
\hline
\end{tabular}

Fonte: elaborada pelos autores, a partir de dados do IBGE. 
Outra questão é que os ganhos de produtividade foram generalizados, neste estado, e somente não ocorreram nas culturas de algodão, erva-mate e sorgo. Essas culturas apresentaram taxas negativas de crescimento da produção, juntamente com arroz e café, nas quais os significativos aumentos de produtividade não foram suficientes para contrabalançar a queda da área colhida. Soja, trigo e cana-de-açúcar, culturas que mais se beneficiaram no processo de substituição de culturas, cresceram a taxas de 6,96,17,27 e 7,63\%, ao ano, respectivamente.

Em Pernambuco, houve expansão do cultivo de canade-açúcar, que ocupou cerca de 55\% da área total substituída no sistema de produção (Tabela 7). Esse crescimento caracteriza, em certa medida, reversão da tendência observada na década anterior. Conforme Moreira (2010), que abordou o período de 1990 a 2008, houve redução expressiva da área cultivada com cana-de-açúcar, no Estado de Pernambuco, na década de 90. Nos anos seguintes, porém, a tendência foi de recuperação da importância da cultura, nesse estado.

Essa recuperação tem sido acompanhada de queda da área colhida com algodão, arroz, batata, café, caju, feijão, laranja e milho, que, em conjunto, perderam cerca de 143 mil hectares, no processo de substituição de culturas (Tabela 7). O feijão e o milho foram as culturas que mais perderam área no processo de substituição, seguidas pelo algodão. Em decorrência da queda da área colhida, e também pela redução dos rendimentos (exceto algodão), ocorreu declínio da produção de algodão, batata-inglesa, café, feijão, laranja e milho. Nos demais casos, o crescimento da área, do rendimento, ou de ambos, asseguraram taxas positivas de aumento da produção.

No Estado de São Paulo, ocorreu movimento significativo de substituição de produtos no sistema produtivo. Esse movimento acarretou queda da área colhida da maior parte das culturas, com destaque para milho, feijão, laranja, algodão, arroz, sorgo e soja (Tabela 8). Como o efeito escala foi positivo, as atividades mencionadas perderam área, em decorrência de sua substituição por outras culturas dentro do sistema. A área cedida por essas culturas no processo de substituição foi, em sua quase totalidade, ocupada com a produção de canade-açúcar.

Apesar do forte processo de substituição de culturas pela expansão da cana-de-açúcar, quedas significativas da produção foram observadas em poucos casos. Essa queda foi mais marcante para algodão, arroz e cebola, mas ocorreu, também, em batata, feijão, laranja, limão, manga e uva. Isso porque os ganhos de produtividade, que foram generalizados, tenderam a reduzir os impactos da queda na área colhida. Em alguns casos, como em amendoim, banana, melancia, milho, soja e sorgo, esses ganhos fo-

Tabela 7 - Decomposição da variação da área (efeitos escala e substituição), em ha, e da taxa de crescimento da produção (efeitos área e rendimento), em \%, das principais culturas no Estado de Pernambuco, período de 2000-2010

\begin{tabular}{|c|c|c|c|c|c|c|c|}
\hline \multirow{3}{*}{ Culturas } & \multicolumn{3}{|c|}{ Variação da área } & \multirow{3}{*}{$\%$} & \multicolumn{3}{|c|}{ Variação da produção } \\
\hline & \multirow{2}{*}{$\begin{array}{c}\text { Variação } \\
\text { total }\end{array}$} & \multicolumn{2}{|c|}{ Efeitos } & & \multirow{2}{*}{ Área } & \multirow{2}{*}{ Rendim. } & \multirow{2}{*}{ Total } \\
\hline & & Escala & Substituição & & & & \\
\hline Algodão herbáceo & $-9752,00$ & $-411,66$ & $-9340,34$ & $-7,55$ & $-20,06$ & 0,79 & $-19,27$ \\
\hline Amendoim & 5,00 & $-2,86$ & 7,86 & 0,01 & 0,65 & 2,27 & 2,92 \\
\hline Arroz & $-705,00$ & $-151,56$ & $-553,44$ & $-0,45$ & $-1,93$ & 2,75 & 0,82 \\
\hline Banana & 8609,00 & $-1390,87$ & 9999,87 & 8,09 & 2,14 & 2,53 & 4,67 \\
\hline Batata-inglesa & $-62,00$ & $-2,34$ & $-59,66$ & $-0,05$ & $-50,00$ & $-50,00$ & $-100,00$ \\
\hline Borracha & 117,00 & $-10,62$ & 127,62 & 0,1 & 3,44 & $-5,09$ & $-1,65$ \\
\hline Café & $-1805,00$ & $-213,85$ & $-1591,15$ & $-1,29$ & $-3,74$ & $-0,92$ & $-4,66$ \\
\hline Cana-de-açúcar & 56754,00 & $-11468,42$ & 68222,42 & 55,16 & 1,73 & 0,92 & 2,65 \\
\hline Castanha de caju & $-523,00$ & $-271,55$ & $-251,45$ & $-0,2$ & $-0,77$ & 5,90 & 5,12 \\
\hline Cebola & 2192,00 & $-114,99$ & 2306,99 & 1,87 & 5,63 & 2,68 & 8,32 \\
\hline Coco-da-baía & 575,00 & $-357,20$ & 932,20 & 0,75 & 0,61 & 6,58 & 7,19 \\
\hline Feijão & $-68950,00$ & $-10283,64$ & $-58666,36$ & $-47,44$ & $-2,85$ & $-1,19$ & $-4,04$ \\
\hline Fumo & 217,00 & $-0,38$ & 217,38 & 0,18 & 37,25 & 3,91 & 41,17 \\
\hline Laranja & $-770,00$ & $-53,86$ & $-716,14$ & $-0,58$ & $-7,41$ & $-0,72$ & $-8,13$ \\
\hline Limão & 387,00 & $-10,55$ & 397,55 & 0,32 & 9,19 & 2,88 & 12,08 \\
\hline Mandioca & 25737,00 & $-1530,45$ & 27267,45 & 22,05 & 5,08 & 1,93 & 7,00 \\
\hline Manga & 3747,00 & $-239,69$ & 3986,69 & 3,22 & 4,78 & 1,72 & 6,50 \\
\hline Melancia & 2451,00 & $-99,02$ & 2550,02 & 2,06 & 6,80 & $-0,41$ & 6,39 \\
\hline Milho & $-61473,00$ & $-8977,60$ & $-52495,40$ & $-42,45$ & $-2,88$ & $-3,84$ & $-6,72$ \\
\hline Sorgo & 3524,00 & $-4,97$ & 3528,97 & 2,85 & 39,38 & $-0,10$ & 39,28 \\
\hline Uva & 4018,00 & $-110,96$ & 4128,96 & 3,34 & 8,97 & $-0,43$ & 8,53 \\
\hline
\end{tabular}

Fonte: elaborada pelos autores, a partir de dados do IBGE.

Rev. Ceres, Viçosa, v. 61, n.4, p. 482-493, jul/ago, 2014 
Tabela 8 - Decomposição da variação da área (efeitos escala e substituição), em ha, e da taxa de crescimento da produção (efeitos área e rendimento), em \%, das principais culturas no Estado de São Paulo, período de 2000-2010

\begin{tabular}{|c|c|c|c|c|c|c|c|}
\hline \multirow{3}{*}{ Culturas } & \multicolumn{3}{|c|}{ Variação da área } & \multirow{3}{*}{$\%$} & \multicolumn{3}{|c|}{ Variação da produção } \\
\hline & \multirow{2}{*}{$\begin{array}{c}\text { Variação } \\
\text { total }\end{array}$} & \multicolumn{2}{|c|}{ Efeitos } & & \multirow{2}{*}{ Área } & \multirow{2}{*}{ Rendim. } & \multirow{2}{*}{ Total } \\
\hline & & Escala & Substituição & & & & \\
\hline Algodão herbáceo & $-53267,00$ & 21523,30 & $-74790,30$ & $-4,28$ & $-15,34$ & 0,47 & $-14,86$ \\
\hline Amendoim & $-22579,00$ & 27849,06 & $-50428,06$ & $-2,88$ & $-3,12$ & 5,51 & 2,39 \\
\hline Arroz & $-41299,00$ & 20256,84 & $-61555,84$ & $-3,52$ & $-10,85$ & 7,93 & $-2,92$ \\
\hline Aveia & 5200,00 & 0,00 & 5200,00 & 0,3 & 0,00 & 0,00 & 0,00 \\
\hline Banana & $-845,00$ & 18567,24 & $-19412,24$ & $-1,11$ & $-0,15$ & 0,74 & 0,59 \\
\hline Batata-inglesa & $-3988,00$ & 9053,40 & $-13041,40$ & $-0,75$ & $-1,55$ & 0,99 & $-0,56$ \\
\hline Borracha & 18746,00 & 9297,53 & 9448,47 & 0,54 & 5,27 & 2,69 & 7,95 \\
\hline Café & $-10016,00$ & 69230,62 & $-79246,62$ & $-4,53$ & $-0,49$ & 0,99 & 0,50 \\
\hline Cana-de-açúcar & 2501844,00 & 813150,15 & 1688693,85 & 96,58 & 7,26 & 1,22 & 8,48 \\
\hline Cebola & $-5083,00$ & 3475,41 & $-8558,41$ & $-0,49$ & $-6,36$ & 1,59 & $-4,77$ \\
\hline Coco-da-baía & 2009,00 & 393,36 & 1615,64 & 0,09 & 10,48 & 3,15 & 13,63 \\
\hline Feijão & $-98395,00$ & 69632,48 & $-168027,48$ & $-9,61$ & $-6,21$ & 6,07 & $-0,13$ \\
\hline Fumo & 119,00 & 43,20 & 75,80 & 0,00 & 6,78 & 4,37 & 11,15 \\
\hline Laranja & $-78201,00$ & 199451,34 & $-277652,34$ & $-15,88$ & $-1,37$ & 1,15 & $-0,22$ \\
\hline Limão & $-10508,00$ & 12018,62 & $-22526,62$ & $-1,29$ & $-3,36$ & 2,68 & $-0,68$ \\
\hline Mandioca & 17885,00 & 11247,62 & 6637,38 & 0,38 & 4,28 & 0,00 & 4,28 \\
\hline Manga & $-8953,00$ & 7008,08 & $-15961,08$ & $-0,91$ & $-5,40$ & 4,88 & $-0,52$ \\
\hline Melancia & $-390,00$ & 2349,66 & $-2739,66$ & $-0,16$ & $-0,56$ & 2,28 & 1,71 \\
\hline Milho & $-315601,00$ & 354857,95 & $-670458,95$ & $-38,35$ & $-3,49$ & 6,27 & 2,78 \\
\hline Soja & $-39906,00$ & 175082,59 & $-214988,59$ & $-12,3$ & $-0,78$ & 2,51 & 1,73 \\
\hline Sorgo & $-41177,00$ & 23789,52 & $-64966,52$ & $-3,72$ & $-8,43$ & 9,97 & 1,54 \\
\hline Trigo & 41341,00 & 4585,44 & 36755,56 & 2,1 & 15,19 & 6,80 & 22,00 \\
\hline Uva & $-661,00$ & 3411,59 & $-4072,59$ & $-0,23$ & $-0,65$ & 0,14 & $-0,52$ \\
\hline
\end{tabular}

Fonte: elaborada pelos autores, a partir de dados do IBGE.

Tabela 9 - Índice de especialização da agricultura nos estados, 2000 a 2010

\begin{tabular}{|c|c|c|c|c|c|c|c|c|}
\hline Ano & $\mathrm{PE}$ & AL & MG & SP & PR & MS & MT & GO \\
\hline 2000 & 3,95 & 2,10 & 5,01 & 3,96 & 3,73 & 2,50 & 2,46 & 3,10 \\
\hline 2001 & 3,46 & 2,00 & 4,90 & 3,87 & 3,85 & 2,78 & 2,34 & 2,97 \\
\hline 2002 & 3,80 & 2,13 & 4,91 & 3,80 & 3,89 & 2,51 & 2,09 & 2,61 \\
\hline 2003 & 3,70 & 1,57 & 5,02 & 3,78 & 3,81 & 2,62 & 2,06 & 2,58 \\
\hline 2004 & 3,92 & 1,98 & 4,99 & 3,75 & 3,78 & 2,41 & 2,15 & 2,47 \\
\hline 2005 & 3,99 & 2,26 & 5,04 & 3,66 & 3,62 & 2,05 & 2,04 & 2,39 \\
\hline 2006 & 4,16 & 2,27 & 5,10 & 3,19 & 3,55 & 2,17 & 1,82 & 2,39 \\
\hline 2007 & 4,07 & 2,18 & 5,07 & 2,73 & 3,44 & 2,44 & 2,22 & 2,76 \\
\hline 2008 & 4,06 & 2,19 & 5,19 & 2,52 & 3,56 & 2,57 & 2,17 & 2,96 \\
\hline 2009 & 4,04 & 2,06 & 5,29 & 2,23 & 3,70 & 2,58 & 2,05 & 2,96 \\
\hline 2010 & 3,96 & 1,80 & 5,38 & 2,18 & 3,41 & 2,68 & 2,04 & 2,80 \\
\hline
\end{tabular}

Fonte: elaborada pelos autores, a partir de dados do IBGE.

ram suficientes para acarretar aumento de produção, apesar da queda da área colhida. A cana, principal beneficiada no processo de substituição, expandiu sua produção a uma taxa média de $8,48 \%$ ao ano, garantida sobretudo pelo crescimento da área colhida.

Resultados semelhantes foram encontrados por Hernández (2008) que, analisando o Estado de São Paulo, constatou forte incemento da área cultivada com canade-açúcar. Esse incremento deu-se sobre a área de culturas alimentares e, principalmente, pela ocupação das áre- as de pastagens. Porém, de acordo com Kohlhepp (2010), a redução de áreas de plantio de gêneros alimentícios no estado foi compensada pela alta da produtividade.

A forte expansão da cana-de-açúcar, em São Paulo e em outros estados, concomitantemente ao menor dinamismo dessa cultura nos estados da região Nordeste, acarretou significativa mudança na distribuição geográfica do setor canavieiro. Essa mudança vem conferindo crescente importância aos estados da região Centro-Sul, na produção de cana-de-açúcar e de seus derivados, como des- 
tacado por Moreira (2010). A produção de cana, segundo a autora, vem-se deslocando da região Nordeste para a Região Centro-Sul, principalmente para o oeste do Estado de São Paulo e para os estados do Centro-Oeste, além de Paraná e Minas Gerais.

Os valores do índice de diversificação, exibidos na Tabela 9, evidenciam tendência de queda da diversificação da agricultura dos estados onde cresceu a participação da cana-de-açúcar e, também, da soja, como se deu em São Paulo, Mato Grosso, Paraná, Goiás e Alagoas. Em São Paulo, especialmente, o índice de especialização reduziu-se praticamente à metade, entre os anos inicial e final do estudo, em decorrência do crescente predomínio da cana-de-açúcar nesse estado. Ao final do período, sua agricultura passa a apresentar índice de diversificação próximo daquele dos estados de Alagoas e Mato Grosso, de agricultura pouco diversificada.

\section{CONCLUSÕES}

Com esta pesquisa, buscou-se analisar os efeitos da expansão da produção de cana-de-açúcar sobre a produção dos demais gêneros, buscando aferir a magnitude do processo de substituição de culturas. Umas das conclusões do estudo é que houve forte expansão da área cultivada com a cana-de-açúcar e a soja, no sistema de produção composto pelos oito estados em análise.

Essa expansão deu-se, em parte, pelo crescimento do sistema produtivo, o que implica dizer que novas áreas, provavelmente de pastagens, foram incorporadas à produção dos gêneros analisados. Por outro lado, o crescimento da produção dessas duas culturas esteve alicerçado na substituição de outros produtos no sistema, destacando-se, principalmente, arroz, feijão e milho, culturas importantes para o abastecimento interno, mas, também, café, algodão e laranja.

Apesar disso, e com exceção do arroz, foram poucos os impactos dessas mudanças na produção dos demais gêneros. A expansão do sistema e, principalmente, o crescimento da produtividade, contribuíram para atenuar e, em certos casos, contrabalançar, os efeitos do processo de substituição sobre o crescimento da produção.

Observou-se, ainda, que as mudanças ocorridas reduziram a diversidade da agricultura, nos estados mais afetados pelo crescimento da participação da cana-de-açúcar e da soja, principalmente, como verificado em São Paulo, Mato Grosso, Paraná, Goiás e Alagoas. Apresentando uma agricultura crescentemente especializada, esses estados tornam-se mais expostos às possíveis consequências, de ordem econômica e social, decorrentes de condições adversas no mercado dos produtos nos quais sua agricultura passou a se basear.
Finalmente, há que se destacar que esta pesquisa não encerra a controvérsia sobre o conflito entre os biocombustíveis, neste caso o etanol, e a produção de alimentos. Para uma análise mais profunda, sobre os impactos dessas mudanças, seria necessário confrontar o crescimento da produção dos alimentos com a evolução da demanda interna, bem como analisar as eventuais necessidades de importações e o comportamento de seus preços. Além disso, não se pode atribuir todas as mudanças ocorridas à expansão da cana-de-açúcar, alvo da pesquisa, ou da soja, cultura que também experimentou forte crescimento no período. Mudanças nas condições do mercado, estímulos da política agrícola, impactos de eventos climáticos, ataque de pragas e doenças, dentre outros eventos, podem afetar de modo diferenciado as culturas estudadas. Por questões diversas, esses fatores não puderam ser abordados nesta pesquisa, o que limita, em parte, as suas conclusões.

\section{REFERÊNCIAS}

Aguiar DA, Silva WF, Rudorff BFT, Sugawara LM \& Carvalho MA (2009) Expansão da cana-de-açúcar no Estado de São Paulo: safras 2003/2004 a 2008/2009. In: 14 Simpósio Brasileiro de Sensoriamento Remoto, Natal. Anais, INPE. p.9-16.

Ávila SRSA, Altafin IG \& Ávila ML (2009) Efeitos da expansão da cultura da cana-de-açúcar: um estudo qualitativo em Rubiataba - Goiás. In: $47^{\circ}$ Congresso da Sociedade Brasileira de Economia e Sociologia Rural, Porto Alegre. Anais, SOBER. p.1-14.

BNDES \& CGE (2008) Bioetanol de cana-de-açúcar: energia para o desenvolvimento sustentável. Rio de Janeiro, BNDES. 316p.

Carvalho HM (2007) Impactos econômicos, sociais e ambientais devido à expansão da oferta do etanol no Brasil. Disponível em <http://www.landaction.org/spip/spip.php? article190>. Acessado em: 10 de julho de 2007.

Correa VHC (2013) O desenvolvimento e a expansão recente da produção agropecuária no Centro-Oeste Publicação. Tese de Doutorado. Instituto de Economia/Universidade Estadual de Campinas, Campinas. 255p.

Gasques JG, Bastos ET, Bacchi MRP \& Valdes C (2010) Produtividade total dos fatores e transformações da agricultura brasileira: análise dos dados dos censos agropecuários. In: $48^{\circ}$ Congresso da Sociedade Brasileira de Economia, Administração e Sociologia Rural, Campo Grande. Anais, SOBER. p. 1-21.

Hernández DIM (2008) Efeitos da produção de etanol e biodiesel na produção agropecuária do Brasil. Dissertação de Mestrado. Faculdade de Agronomia e Medicina Veterinária/UnB, Brasília. $163 \mathrm{p}$.

Hoffmann R (2006) Segurança Alimentar e Produção de Etanol no Brasil. Segurança Alimentar e Nutricional, 13:01-05.

Instituto Brasileiro de Geografia e Estatística (2011) Sistema de Recuperação Automática - SIDRA. Disponível em: <www.sidra.ibge.gov.br>. Acessado em: 15 de março de 2011.

Kohlhepp G (2010) Análise da situação da produção de etanol e biodiesel no Brasil. Estudos avançados, 68:223-253.

Libardi D \& Cardoso NA (2007) Cana-de-açúcar: a salvação da lavoura ou do planeta? Análise Conjuntural, 29:24-26.

Ministério da Agricultura, Pecuária e Abastecimento (2009) Anuário Estatístico da Agroenergia. Brasília, Mapa/ASC. 160p. 
Moreira RCGGS (2010) Segurança alimentar x agrocombustíveis a controvérsia entre a produção de alimentos e a produção de etanol no Brasil. Dissertação de Mestrado. Escola Nacional de Ciências Estatísticas/Instituto Brasileiro de Geografia e Estatística, Rio de Janeiro. 150p.

Oliveira ICC, Neder HD \& Almeida filho N (2010) Impactos Sociais da Expansão do Programa de Biocombustíveis sobre o estado de Minas Gerais. In: $14^{\circ}$ Seminário sobre Economia Mineira, Diamantina. Anais, CDEPLAR. p.1-20.

Palomino JMG, Toneto Junior R, Campos CVC \& Stocco L (2008) A expansão da cana-de-açúcar e o impacto sobre a arrecadação fiscal dos municípios paulistas. In: $46^{\circ}$ Congresso da Sociedade Brasileira de Economia, Administração e Sociologia Rural, Rio Branco. Anais, SOBER. p.1-21.
Ribeiro VH, Gonçalves Junior FA \& Paiva RG (2013) Transformações da paisagem rural da microrregião de paranavaí-PR e a expansão da cana-de-açúcar nos municípios de Tamboara e Itaúna do sul de 1970-2012. Revista Percurso, 5:55-86.

Silva A, Oliveira DE \& Lima DALL (2010) Segurança Alimentar: estudo sobre a produção de alimentos em Goiás, 19902009. In: 5 . Encontro Nacional da ANPPAS, Florianópolis. Anais, ANPPAS. p.1-20.

Yokoyama LP, Igreja ACM. \& Neves EM (1989) Modelo shiftshare: uma readaptação metodológica e uma aplicação para o Estado de Goiás. In: $27^{\circ}$ Congresso brasileiro de economia e sociologia rural, Piracicaba. Anais, SOBER. p.63-78. 